\title{
HISTOPATHOLOGICAL PROFILE OF THE GASTROINTESTINAL POLYPS IN KASHMIR VALLEY
}

\author{
Shaziya Ashraf ${ }^{1}$, Syed Besina Yasin ${ }^{2}$, Subuh Parvez Khan *3, Mushtaq Ahmad Khan ${ }^{4}$, \\ Farhat Abbas ${ }^{5}$. \\ ${ }^{1}$ MD Pathology, Resident, Department of Pathology, Sher E Kashmir Institute of Medical Sciences Srinagar Kashmir, \\ India. \\ ${ }^{2}$ MD Pathology, Additional Professor And Head of the Department, Department of Pathology, Sher E Kashmir \\ Institute Of Medical Sciences, Srinagar, Kashmir, India. \\ ${ }^{* 3}$ MD Pathology,Senior Resident, Department of Haematopathology, Sher E Kashmir Institute of Medical Sciences \\ ,Srinagar, Kashmir, India. \\ ${ }^{4} \mathrm{MD}$ Internal Medicine, Dm Gastroenterology, Professor, Department of Gastroenterology, Sher E Kashmir Institute \\ of Medical Sciences, Srinagar, Kashmir, India. \\ ${ }^{5}$ MD Pathology, Resident, Department of Pathology, Sher E Kashmir Institute Of Medical Sciences Srinagar Kashmir, \\ India.
}

\section{ABSTRACT}

Introduction: A gastrointestinal (GI) polyp is a discrete mass protruding into the lumen of GI Tract projecting above the plane of the mucosal surface. Polyp may be neoplastic and neo-neoplastic in nature. Determining the potential risk of malignancy of the polyp is very important for the purpose of line of treatment. The polyp size and histological types are important factors for development of cancers in polyps.

Materials and Methods: This was a five year observational study conducted from 2012-2016. All the patients diagnosed with true Gastro-intestinal polyps enrolled in Sher-i-Kashmir Institute of Medical Sciences, Kashmir were analyzed. Data regarding the clinico-pathological parameters was collected. Gastrointestinal polyps were grouped as per age, location, number, presence and absence of stalk, presence and absence of dysplasia; and histological type. The data was analyzed using the statistical software SPSS version V 20.

Results: Among 595 patients reported, 373 (62.7\%) were males and 222 (37.3\%) were females. The age of the patients ranged from 1 to 90 years. Mean age was 40 years. Majority of the polyps (74\%) were found in large intestine. $63.19 \%$ were non-neoplastic and $36.8 \%$ were neoplastic. $90.76 \%$ percent of the patients presented with single polyps. Sessile polyps were seen in $90.76 \%$. Majority of cases had adenomatous polyps (36.8\%), followed by hyperplastic polyps (30.92\%). The sub types of the adenomatous polyps were tubulovillious with $56.22 \%$ followed by tubular and villious type with $28.31 \%$ and 15.06 \%respectively. Among adenomatous polyps, $62.10 \%$ were with dysplasia while $37.90 \%$ were without dysplasia. Four cases of Familial Adenomatous polyposis (FAP) were observed. 15 patients presented with 9 synchronous and 6 metachronous lesions .

Conclusion: The high prevalence of adenomatous polyps in our study warrants need of screening for early detection and prevention of colorectal carcinomas. Genetic and molecular screening evaluation may also have a huge impact on understanding the mechanism of neoplastic polyps.

KEY WORDS: Polyps, Gastrointestinal, Histopathology.

Address for correspondence: Dr Subuh Parvez Khan, MD Pathology, Senior Resident, Department of Haematopathology, Sher E Kashmir Institute Of Medical Sciences, Srinagar, Kashmir, 190011, India.E-Mail: khansubuh@gmail.com

\begin{tabular}{|l|l|}
\hline \multicolumn{3}{|c|}{ Online Access and Article Informtaion } \\
\hline Quick Response code & \multicolumn{2}{|c|}{ International Journal of Integrative Medical Sciences } \\
& \multicolumn{1}{c|}{ ISSN (P): 2394 - 6318. ISSN (E): 2394 - 4137 } \\
www.imedsciences.com
\end{tabular}




\section{BACKGROUND}

A gastrointestinal (GI) polyp is a discrete mass protruding into the lumen of GI Tract [1] projecting above the plane of the mucosal surface [2].

Although more than $90 \%$ of the polyps are asymptomatic, but larger polyps may present with bleeding, anemia, obstruction, or abdominal pain [3]. They may be neoplastic and neoneoplastic in nature. Determining the potential risk of malignancy of the polyp is very important for the purpose of line of treatment. The polyp size and histological types are important factors for development of cancers in polyps [4] The larger the amount of villous portion and size of the polyp, the higher is the risk of malignancy [5]. The frequency and distribution of gastrointestinal polyps may vary in different populations according to genetic, socioeconomic status and life habits [6]. Genetic susceptibility ranges from well-defined inherited syndromes, e.g. familial adenomatous polyposis, to ill-defined familial aggregations.

\section{Aim:}

To determine the distribution and histopathological characteristics of gastrointestinal polyps in Kashmir valley.

\section{MATERIALS AND METHODS}

This was a five year observational study conducted from 2012-2016. All the patients diagnosed with true Gastro-intestinal polyps enrolled in Sher-i-Kashmir Institute of Medical Sciences, Kashmir were analyzed. Endoscopic/colonoscopic description and histological findings of all the patients diagnosed with polyps were noted. Data regarding the clinico-pathological parameter including age, site, number, histological features, presence and absence of stalk, and type of the polyp was collected. Association of the degree of dysplasia with site and type of the polyp was assesed. Gastrointestinal polyps were grouped as per age, location, number, presence and absence of stalk, presence and absence of dysplasia; and histological type. Approval by the Institutional Ethical Committee was obtained for this study The data was analyzed using the statistical software SPSS version $\mathrm{V} 20$.

\section{RESULTS}

Among 595 patients reported, 373 (62.7\%) were males and 222 (37.3\%) were females. The age of the patients ranged from 1 to 90 years. Mean age was 40 years with maximum number of cases viz; $106(17.82 \%)$ seen in the age group of 51-60 years. Present study included both adult as well as pediatric population. Distribution of polyps on the basis of location is shown in Table 1. We followed the anatomic distribution of these polyps at the level of colon as shown in Table 2. Out of $595 \mathrm{Gl}$ polyps detected, 376 (63.19\%) were non-neoplastic and 219 (36.8\%) were neoplastic. As far as the number of polyps is concerned, $90.76 \%$ percent of the patients presented single polyps while only $9.24 \%$ percent were multiple polyps.Figure 1 shows colonoscopic view of a polyp. 540 cases (90.76\%) were sessile polyps while only 55 (9.24\%) polyps were pedunculated. Distribution of Gastrointestinal Polyps on the basis of histological impressions in shown in Table 3.

The sub types of the adenomatous polyps were tubulovillious with $56.22 \%$ followed by tubular and villious type with $28.31 \%$ and $15.06 \%$ respectively. Out of the 219 cases of adenomatous polyps, $62.10 \%$ were with dysplasia while $37.90 \%$ were without dysplasia (Table 4). Four cases of Familial Adenomatous polyposis (FAP) were observed in this five year study period. Out of which three were male patients. Histologically, they were all adenomatous polyps. Dysplasia was low grade in one case while high grade in other 3 cases. No tumor was reported in any of the cases. Figure 2 shows a resected colon specimen of FAP with multiple poyps.

Between the year 2012-2016, 15 patients (10 male and 5 females) with age ranging from 40 to 75 years with 9 synchronous and 6 metachronous lesions were observed. The diagnosis lag for metachronous lesions was 2-10 years. All nine patients with synchronous cancers had two lesions. The tumour was located more frequently in the rectum followed by descending colon. All six metachronous lesions had undergone curative surgery for primary colorectal carcinoma and were on follow up. Histopathologically, the first primary tumour of synchronous lesion was adenocarcinoma. 
Fig. 1: Single sessile Polyp- Colonscopic View.

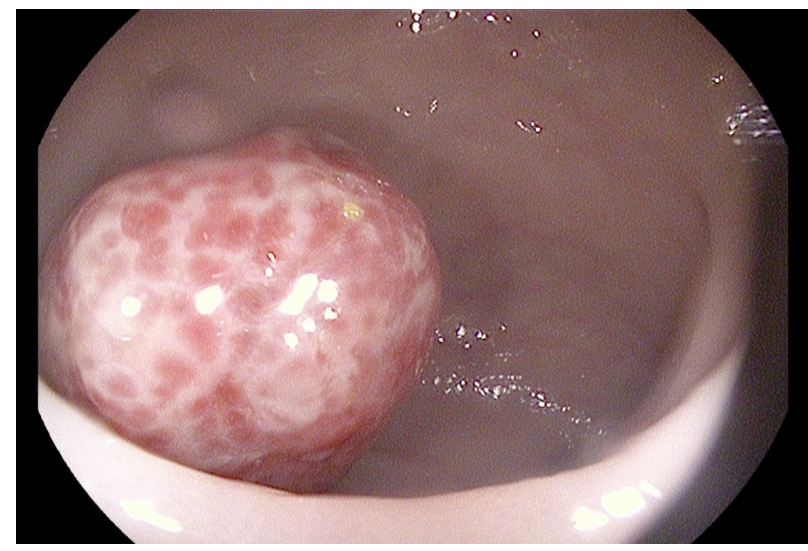

Fig. 2: Gross photograph of resected colon from a patient with Familial Adenomatous Polyposis.

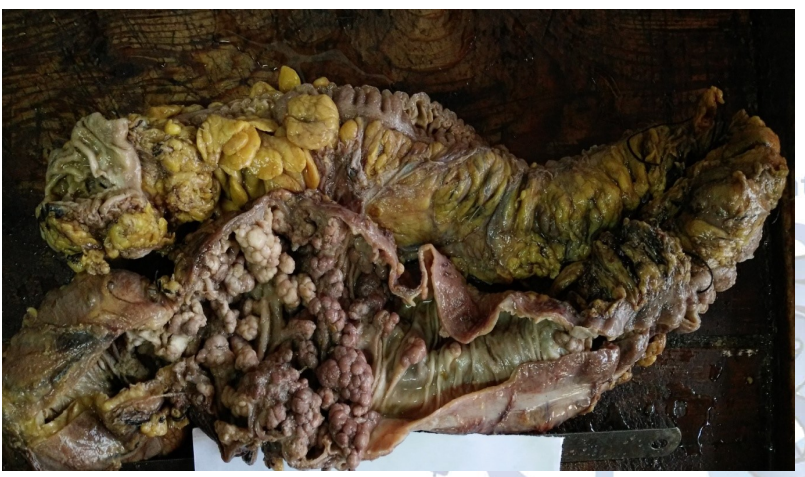

Fig. 3: Photomicrograph showing low power view of Hyperplastic polyp.

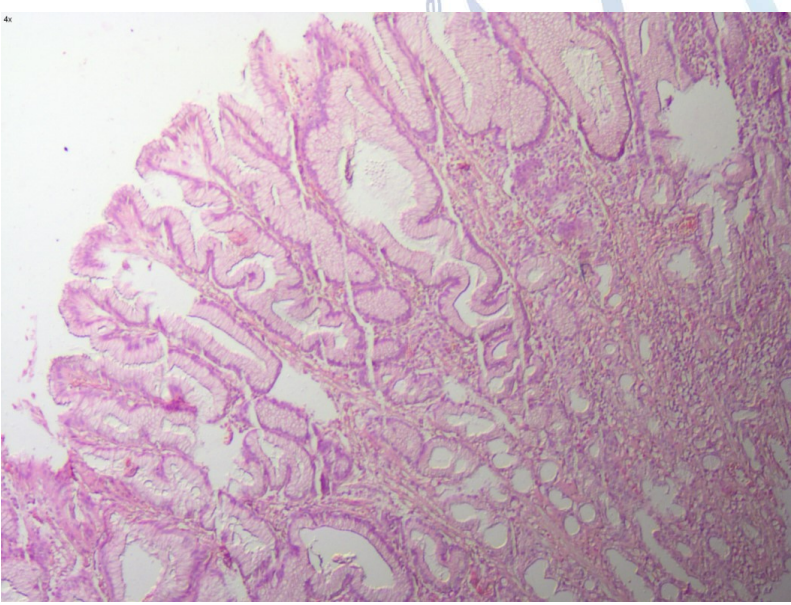

Fig. 4: Photomicrograph showing low power view of Tubular Adenoma-Adenomatous polyp (low grade)

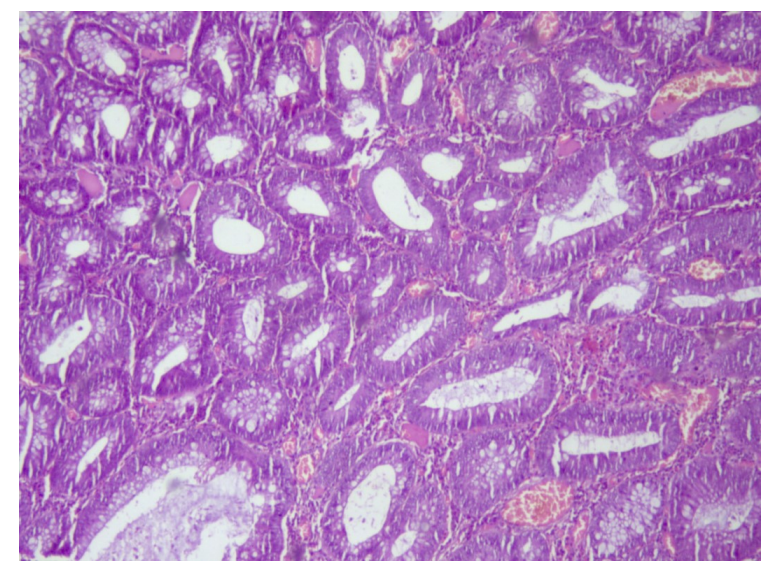

Table 1: Distribution of Gastrointestinal Polyps on the basis of gender, age, location and histological impressions.

\begin{tabular}{|c|c|c|c|c|c|c|}
\hline \multirow{2}{*}{ Age } & Male & Female & & & & \\
\cline { 2 - 7 } & $62.70 \%$ & $37.30 \%$ & & & & \\
\hline \multirow{2}{*}{ Age } & $<40$ & $>40$ & & & & \\
\cline { 2 - 7 } & $45.72 \%$ & $54.28 \%$ & & & & \\
\hline \multirow{2}{*}{ Location } & Gastric & $\begin{array}{c}\text { Large } \\
\text { intestine }\end{array}$ & $\begin{array}{c}\text { Small } \\
\text { intestine }\end{array}$ & & & \\
\cline { 2 - 7 } & $23.87 \%$ & $74.79 \%$ & $1.34 \%$ & & & \\
\hline \multirow{2}{*}{ Histology } & Adenomatous & Hyperplastic & Juvenile & Inflammatory & Retention & $\begin{array}{c}\text { Peutz } \\
\text { Jeghers }\end{array}$ \\
\cline { 2 - 7 } & $36.80 \%$ & $30.92 \%$ & $16.47 \%$ & $7.39 \%$ & $6.72 \%$ & $1.68 \%$ \\
\hline
\end{tabular}

Table 2: Distribution of polyps in colon.

\begin{tabular}{|c|c|c|}
\hline Location in colon & $\begin{array}{c}\text { Number of } \\
\text { cases }\end{array}$ & $\begin{array}{c}\text { Percentage of } \\
\text { cases }\end{array}$ \\
\hline rectum & 289 cases & $(64.94 \%) ;$ \\
\hline ascending colon & 84 cases & $(18.8 \%) ;$ \\
\hline sigmoid colon & 41 cases & $(9.21 \%) ;$ \\
\hline descending colon & 12 cases & $(2.70 \%) ;$ \\
\hline caecum & 7 cases & $(1.57 \%) ;$ \\
\hline spleenic flexure & 7 cases & $(1.57 \%) ;$ \\
\hline transverse colon & 5 cases & $-1.12 \%$ \\
\hline
\end{tabular}

Table 3: Histological classification of polyps.

\begin{tabular}{|c|c|c|}
\hline Histological type & Number of cases & Percentage of cases \\
\hline adenomatous polyp & 219 patients & $-36.80 \%$ \\
\hline hyperplastic polyp & 184 cases & $-30.92 \%$ \\
\hline juvenile polyp & 98 cases & $-16.47 \%$ \\
\hline inflammatory polyp & 44 cases & $-7.39 \%$ \\
\hline retention polyp & 40 cases & $-6.72 \%$ \\
\hline Peutz Jeghers polyp & 10 cases & $(1.68 \%)$. \\
\hline
\end{tabular}

Table 4: Distribution of Adenomatous polyps.

\begin{tabular}{|c|c|c|c|c|c|}
\hline $\begin{array}{c}\text { Type of } \\
\text { adenomatous } \\
\text { polyps }\end{array}$ & $\begin{array}{c}\text { Total } \\
\text { cases }\end{array}$ & $\begin{array}{c}\text { No. of cases } \\
\text { with Dysplasia }\end{array}$ & $\begin{array}{c}\text { No. of cases } \\
\text { with LGD }\end{array}$ & $\begin{array}{c}\text { No. of cases } \\
\text { with MGD }\end{array}$ & $\begin{array}{c}\text { No. of cases } \\
\text { with HGD }\end{array}$ \\
\hline Tubullovillous & 124 & 72 & 28 & 9 & 37 \\
\hline Tubular & 62 & 45 & 26 & 9 & 10 \\
\hline Villious & 33 & 17 & 4 & 1 & 12 \\
\hline
\end{tabular}

$\chi^{2}=14.71, \mathrm{P}=0.005$ significant

Statistically, there is a significant association between adenomatous Gastro intestinal polyps on the basis of grade of dysplasia.

\section{DISCUSSION}

Gastrointestinal malignancy is a global oncological problem [7]. Kashmir is a very high risk area for cancer of the gastrointestinal tract, which comprises more than half the frequency of all the cancers [8].

In our five year study period (2012-2016), we found 595 gastrointestinal polyps, among them $62.7 \%$ were males while $37.3 \%$ were females. 
Our observations of predominant male involvement are consistent with the number of studies from world including Kingdom of Saudi Arabia and Iran [6,9]. In our study, the mean age of the patients with gastrointestinal polyp was 40.64 years. In the literature of gastrointestinal polyps, Albasri et al. [9] from KSA and Yousuf et al. [10] from Iran have reported the mean age of patients with gastrointestinal polyps of 43.2 years and 49 years respectively. The age of the patients with gastrointestinal polyps in our study ranged from 1-90 years. The study from Mangalore by Kunjumon et al. [11] also reported the minimum age of patient with gastrointestinal polyp as 1 year. Out of 595 cases, $74 \%$ were found in large intestine, $25 \%$ in the gastric region while only $1 \%$ was present in small intestine. Similar results were reported by Khujuria et al. [12] from northern part of India wherein, they reported that the maximum number of polyps were present in large intestine $(78.43 \%)$ followed by stomach with $16.67 \%$.

Determining the prevalence of gastrointestinal neoplasms in various anatomical sites can be an important factor to select the favorable modality of screening. In the present study as per the anatomic distribution, most of the polyps were found in the rectum (65\%). Histopathologically, retention polyp was the commonest polyp seen in the rectum (45\%) (Figure 3) .The observation is similar to the study of Tony et al. [13] and Iravani et al. [14] who also reported that the rectum is the most common site of gastrointestinal polyp in south Indian and Iranian population.

Most of the polyps in our study were single (91\%) while only $9 \%$ were multiple. Yoon et al. [15] in their study from Korea also reported that $89.2 \%$ of the polyps were single while only $10.18 \%$ were multiple polyps. Similarly, Buyukasik et al. [16] reported that $88.14 \%$ of the polyps in Turkey population were single type while only $11.86 \%$ as multiple type.

Regarding the histological subtypes of 595 polyps cases, there were 219 adenomatous polyps (36.8\%), followed by 184 hyperplastic polyps (30.92\%). Iravani et al. [14] in their study also reported that the most prevalent type of polyp was adenomatous (34.7\%), followed by hyperplastic (31.1\%) (2014). Albasri et al. [9]
From Kingdom of Saudia Arabia reported that out of 224 polyps, there were 166 adenomatous polyps (74.1\%) followed by 24 hyperplastic polyps (10.7\%) 2014). Similar results were reported by Mirzaie et al [6] and Geramizadeh B et al [1].

Most of the polyps found in our study were sessile (91\%) polyps while only $9 \%$ were pedunculated. Our results were in agreement with the study of Gencosmanoglu et al. [17] and Garcia et al. [18], who reported $95.3 \%$ and $90.8 \%$ polyps were sessile respectively.

Regarding the histological subtype of 219 adenomatous polyps in our study, we observed 124 were tubulovillous (56.22\%) followed by 62 tubular polyps (28.31\%) and 33 were villous adenoma (15.06\%). This is in consistence with the study carried out by Albasri et al [9] in KSA who also reported tubulovillous as most common type of polyp with $61.4 \%$ followed by tubular with $24.7 \%$.

In our study, $62.10 \%$ of the adenomatous polyps were dysplastic(Figure 4) while 37.90 were without dysplasia. Similar results were observed in Iranian population by Geramizadel B [1] wherein they reported $66.77 \%$ dysplastic adenomatous polyps.

In our study, tubullovillous adenomatous polyps were frequently associated with dysplasia (54.41\%) as compared to tubular (33.09\%) and villous type (12.50\%). It was also observed that there were $43.38 \%$ of high grade adenomatous polyps. High grade dysplasia was more associated with villous (78.58\%) and tubullovillous adenomatous (50.0\%) polyps as compared to the tubular type. Similar observations were made by Mirzaie et al. [6] who studied 240 polyps and concluded that the amount of villous component were strongly associated with high grade dysplasia. Albasri et al. [9] 2014 also reported that tubullovillous adenomatous polyps were associated with higher rates of dysplasia as compared to tubular type.

Out of $595 \mathrm{Gl}$ polyps detected, 376 (63.19\%) were non-neoplastic and 219 (36.8\%) were neoplastic. Similar results were observed in an Iranian population by Sohrabi et al. [19] who also found that non-neoplastic polyps in majority of cases than neoplastic cases. Further, out of 453 
colorectal polyps, 99 (21.85\%) were right sided polyp and $354(78.14 \%)$ were left sided polyps. These results were in agreement with the Mirzaie et al [6] who also found that out of 240 polyps 193 (80.4\%) were left sided.

15 patients ( 10 male and 5 females) with age ranging from 40 to 75 years with 9 synchronous and 6 metachronous lesions were observed. The synchronous and metachronous colorectal carcinoma in our study have an incidence of $2.52 \%$. Same results were observed by Papadopoulos et al. [20] during their 5 year study wherein they reported the incidence of synchronous and metachronous carcinoma of $2-10 \%$. The co-existence of adenomatous polyp is considered as a risk factor for the development of metachronous lesions. Primary colorectal carcinomas were associated with multiple adenomatous polyps mostly in rectum and descending colon. Patients with colorectal carcinoma must be followed up regularly after surgery. Follow up aims at early diagnosis and treatment of metachronous lesions that can appear many years after diagnosis of primary lesions.

Four cases of Familial Adenomatous polyposis were observed in our five year study period. Out of which three were male patients while only one was female. Histologically, they were all adenomatous polyps. Dysplasia was low grade in one FAP case while high grade in other 3 cases. No tumor was reported in any of the cases. Proctocolectomy has been done in all the four patients. Polyposis inevitably progresses to colorectal cancer, if left untreated [21]. Screening for colorectal cancer in FAP associated cases must be based on the personal and family history of adenomas and cancer. Follow up of the reported FAP cases through genetic testing was not done due lack of facilities in our centre.

\section{CONCLUSION}

The high prevalence of adenomatous polyps in our study warrants need of screening for early detection and prevention of colorectal carcinomas. Genetic and molecular screening evaluation may also have a huge impact on understanding the mechanism of neoplastic polyps.

\section{REFERENCES}

[1]. Geramizadeh B, Jahromi MK. Pathology of colorectal polyps: A study from south of Iran. Ann Colorectal Res. 2013 Sep; 1: 59-61.
[2]. Sezgin V, Zehra A, Emrah A, Serkkan I, Nafi Y, Nese E et al. Gastric polyps and polypoid lesions: retrospective analysis of 36650 endoscopic procedures in 29940 patients. Turk J of Gastroenterol. 2015 Mar; 26:117-22.

[3]. Islam RS, Neal CP, Dora LH, Cuong CN. Gastric polyps: A review of clinical, endoscopic and histopathologic features and management decisions. Gastroenterol Hepatol. 2013 Oct; 9 (10): 640-651.

[4]. Itzkowitz SH. Gastrointestinal adenomatous polyps. Semin Gastrointest Dis. 1996 Apr; 7(2):105-16.

[5]. Aldridge AJ, Simson JN. Histological assessment of colorectal adenomas by size. Are polyps less than $10 \mathrm{~m}$ in size clinically important Eur J Surg. 2001 Oct; 167(10): 777-81.

[6]. Mirzaie AZ, Maryam A, Roozbeh MM, Maryam K. The frequency of gastrointestinal polyps in Iranian population. Iran J of Pathol. 2012; 7(3): 183-189.

[7]. Jamal Sahid, Mamoon Nadira, Mushtaq S, Luqman M. Analysis of gastrointestinal malignancies at the armed forces institute of pathology, Rawalpindi, Pakistan. Asian Pac J of cancer prev. 2005 (OctDec); 6 (4): 497-500.

[8]. Pandith A, Siddiqi M. Burden of cancers in the valley of Kashmir-5 year epidemiological study reveals a different scenario. Tumor Biol. 2012 Oct; 33 (5): 1629-1637.

[9]. Albasri A, Hala Y, Akbar H, Bukhari S, Ahmad Alhujaily. Profile of colorectal polyps: a retrospective study from King Fahad hospital, Madinah, Saudi Arabia. Asian Pac J Cancer Prev. 2014; 15 (6): 2669-2673.

[10]. Yousuf B, Daghestani D, Esmaili H. Demographic and anatomical survey of colorectal polyps in an Iranian population. Asian Pac J Cancer Prev. 2005 Oct-Dec; 6: 537-40.

[11]. Kunjumon DT, Jinu AG, Pushpalatha KP. A histopathological study of 23 cases of benign epithelial polyps of intestine. Int. J Biomed Res. 2014; 5(2): 117120.

[12]. Khajuria M; Bhardwaj S, and Kumari R. A study into the patterns of gastrointestinal tract polyps. JK Sci. 2016 Apr-Jun; 18 (2): 81-84.

[13]. Tony J, Harish K, Ramachandran TM, Sunilkumar K, Thomas V. Profile of colonic polyps in a southern Indian population. Ind J Gastroenterol. 2007 MayJun; 26: 127-29.

[14]. Iravani S, Kshfi SMH; Azimzadeh P; Lashkari MH. Prevalence and characteristics of colorectal polyps in symptomatic and asymptomatic Iranian patients undergoing colonscopy from 2009-2103. Asian Pac J Cancer Prev. 2014; 15 (22): 9933-9937.

[15]. Yoon WJ, Lee DH, Jung YJ, Jeong JB, Kim JW, Kim BG, et al. Histologic characteristics of gastric polyps in Korea: Emphasis on discrepancy between endoscopic forceps biopsy and endoscopic mucosal resection specimen. World J Gastroenterol. 2006 July; 12 (25): 4029-4032.

[16]. Buyukasik K, Mert MS, Umut RG, Ari A, Gurbulak B, Toros $A B$ et al. Upper gastrointestinal tract polyps: What do we know about them? Asian Pac J Cancer Prev. 2015; 16 (7): 2999-3001. 
[17]. Gencosmanoglu R, Sen OE, Kurtkaya YO, Avsar E, Sav A, Tozun N. Gastric polypoid lesions: analysis of 150 endoscopic polypectomy specimens from 91 patients. World J Gastroenterol. 2003 Oct; 9(10): 2236-9.

[18]. García FJ, Martín RM, González JA, Foruny JR, Vazquez E, Boixeda DM. Gastric polyps: analysis of endoscopic and histological features in our center. Rev Esp Enferm Dig (Madrid). 2011 Aug; 103(8):416-420.

[19]. Sohrabi M, Farhad Z, Hossien A, Naser R, Mitra A, Mehdi $\mathrm{M}$ et al. Prevalence of colorectal polyps in a group of subjects at average-risk of colorectal cancer undergoing colonoscopic screening in Tehran, Iran between 2008 and 2013. Asian Pac J Cancer Prev. 2014; 15 (22): 9773-9779.
[20]. Papadopoulos V, Michalopoulos A, Basdanis G, Popapolychroniadis K, Paramythiotis, Fotiadis $\mathrm{P}$ et al. Synchronous and metachronous colorectal carcinoma. Tech Coloproctol. 2004 Nov; 8 (1): 97-100.

[21]. Kim B, Francis MG. Chemoprevention in familial Adenomatous polyposis. Best Prac Res Clin Gastroenterol. 2011 Aug; 25(4-5): 607-622.

How to cite this article: Shaziya Ashraf, Syed Besina Yasin, Subuh Parvez Khan, Mushtaq Ahmad Khan, Farhat Abbas. HISTOPATHOLOGICAL PROFILE OF THE GASTROINTESTINAL POLYPS IN KASHMIR VALLEY. Int J Intg Med Sci 2018;5(6):644-649. DOI: 10.16965/ijims.2018.115 